\title{
ERRATUM
}

\section{Correction to: Excess Weight Gain After Cure of Hepatitis C Infection with Direct-Acting Antivirals}

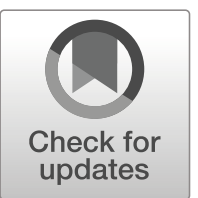

\author{
Albert Do, M.D. M.P.H. ${ }^{7}$, Denise A. Esserman, Ph.D. ${ }^{2}$, Supriya Krishnan, Sc.D. ${ }^{3,4}$, \\ Joseph K. Lim, M.D. ${ }^{1.4}$, Tamar H. Taddei, M.D. ${ }^{1.4}$, Ronald G. Hauser III, M.D. ${ }^{4,5}$, \\ JanetP. Tate, M.P.H. SC.D., ${ }^{3,4}$, Vincent Lo Re III, M.D., ${ }^{6,7}$, and Amy C. Justice, M.D., Ph.D.,4
}

\begin{abstract}
'Section of Digestive Diseases, Department of Internal Medicine, Yale University School of Medicine, 333 Cedar St, 1080 LMP, New Haven, CT, USA; ${ }^{2}$ Department of Biostatistics, Yale University School of Public Health, New Haven, CT, USA; ${ }^{3}$ Department of Internal Medicine, Yale University School of Medicine, New Haven, CT, USA; ${ }^{4}$ VA Connecticut Healthcare System, West Haven, CT, USA; 5 Department of Laboratory Medicine, Yale University School of Medicine, New Haven, USA; 'Division of Infectious Diseases, Department of Medicine, Perelman School of Medicine, University of Pennsylvania University of Pennsylvania, Philadelphia, PA, USA; ${ }^{7}$ Center for Clinical Epidemiology and Biostatistics, Department of Biostatistics, Epidemiology, and Informatics, Perelman School of Medicine, University of Pennsylvania, Philadelphia, PA, USA.
\end{abstract}

J Gen Intern Med 35(10):3140

DOI: $10.1007 / \mathrm{s} 11606-020-06227-\mathrm{w}$

(c) Society of General Internal Medicine 2020

$\mathbf{C}$

ORRECTION TO: J GEN INTERN MED 35(7):2025-34

https://doi.org/10.1007/s11606-020-05782-6

JGIM published the article matched with the editorial in this issue in the July 2020 issue. Our apologies to the authors of the paper and the editorial.

Corresponding Author: Albert Do, M.D. M.P.H.; Section of Digestive Diseases, Department of Internal Medicine, Yale University School of Medicine, 333 Cedar St, 1080 LMP, New Haven, CT, USA (e-mail: albert.do@yale.edu).

Publisher's Note: Springer Nature remains neutral with regard to jurisdictional claims in published maps and institutional affiliations.

The online version of the original article can be found at https://doi.org/10. 1007/s11606-020-05782-6

Published online October 6, 2020 